\title{
Cardiovascular Signaling Malfunction Induced by Stored Blood Transfusion
}

\section{Pedro Cabrales*}

University of California, San Diego, Department of Bioengineering, Gilman Drive La Jolla, CA, USA

RBCs are essential for oxygen transport; their changes in content and structure are fundamental component of several pathological conditions and consequences (e.g. anemia, spherocytosis, elliptocytosis, erythrocyte parasitic diseases, etc). RBCs are currently stored in blood banks up to 42 days at $4^{\circ} \mathrm{C}$. During storage, cells undergo progressive biochemical changes, modifying RBC dynamics when transfused. Blood is transfused to treat insufficient oxygen carrying capacity. Whereas oxygen transport capacity is invariably restored, by increasing the number of circulating cells, stored blood transfusions do not achieve its intended goal. Blood storage produces biochemical changes that affect cell molecular structure and mechanical properties that affect the interaction between RBCs and the vasculature.

The only practical treatment for massive hemorrhage and acute anemia is blood transfusion. Approximately 14 million blood units are transfused annually in the U.S [1]. Blood safety has been improved during the past 20 years, significantly reducing the risk of infection and the immune response to transfusion [2]. Paradoxically, blood transfusion has been shown to provide no benefit in some patients, and has been associated with increased morbidity and mortality $[3,4]$. Several studies have indicated that the transfusion of stored blood for more than 14 days decreased microcirculatory oxygen delivery [5], increased tissue hypoxia [6], and affected outcome [5,7]. A recent systematic review and metaanalysis that evaluated the efficacy of stored blood transfusion (including 272,596 patients) revealed that, in 42 of 45 studies, the risk of transfusion outweighed the benefit by increasing mortality by $70 \%$ [8]. In addition, several studies have shown that survival rate decreases with mean blood storage duration, and that storage duration is a strong predictor and risk factor of multiple-organ failure $[5,8]$. Retrospective studies of adverse outcomes to transfusion of stored blood showed a linear relationship between mortality and storage blood age [9]. Given that these studies clearly raise a concern regarding several problems associated with transfusion of stored blood. Thus, a mechanistic and systematic analysis of the biochemical, structural, and functional changes in erythrocytes after ex vivo ageing (storage) is essential to improve transfusion medicine.

During blood storage, the molecular components of erythrocytes undergo progressive biochemical alterations. These alterations affect erythrocytes constitutive properties and change their structure and function [10-13]. These changes are called "blood storage lesions", and comprise cell shape, deformability, viscosity, membrane oxidation (resulting in lipid, carbohydrates and proteins degradation), changes in oxygen affinity, adhesion molecules, and microvesicles formation [10]. Blood storage lesions affect transfused cells circulatory mechanics, hydrodynamics and their function. We and others have independently analyzed some of the storage induced changes, and have identified that the cell deformability is the most significant factor, that affects blood flow, oxygenation and overall circulatory function [14,15]. Previously, changes in deformability were associated with the ability of cells to pass through microcirculatory beds, and cell lifespan.

Studies have shown that RBCs participate in blood flow regulation through chemical signaling and contribute to blood viscosity through their individual motion, which is affected by changed in deformability
[8,11,12,14-16]. Mechanical change in the RBC affects its release of ATP, which acts as a signaling molecule in the blood plasma, and triggers the release of nitric oxide (NO) from endothelial cells and produces vasodilation. This idea indicates that RBCs are not just inert bags of $\mathrm{Hb}$, but rather are paracrine signaling the vessel wall. From the hemorheological macroscopic view, blood viscosity determines endothelial mechanotransduction and it is affected by hematocrit, plasma viscosity, cell aggregation, and cell deformability.

There is a lack of studies analyzing the interaction of blood with the vasculature due to limited quantitative methods to analyze blood flow in vivo; in addition to studies linking macro-scale shear viscosity, microvascular blood flow, cell hydrodynamics, ATP release, NO production by the endothelium and changes in vascular tone. These topics have to be treated pair-wise, although, they are linked and have not been fully explored, to obtain a multiscale view of RBCs, connecting rheology with cell dynamics to vascular shear mechanotransduction. Unraveling the links between ATP release from RBCs and shear mediated NO production with cellular-scale mechanical responses may provide insight into cardiovascular pathologies and therapeutics. Both NO and ATP are a well-established vasodilators, involved in many cardiovascular diseases, and are linked by RBC deformability. It is not surprising that he complications associated with transfusion of stored blood are due to hemodynamic disturbances caused by the structural and signaling changes, affecting the exchange of signals between the flowing blood cells and the blood vessels.

The central theme for future work needs to create a hierarchical analysis to establish the link between hemodynamic alterations that created changes in cellular dynamic with chemical and mechanical signaling between the flowing RBCs and the blood vessels. Approaches should include experimental and computational techniques, to quantitatively understand the effects of molecular structural changes during blood storage on $\mathrm{RBC}$ mechanically induced structural remodeling using multiscale framework. The hypothesis that changes during storage in the RBC structure are responsible for impairing membrane and cell mechanics has to be examined, including the effects on cell dynamic in shear flow (cells tumbling (an end-over-end rigid body rotation) and tank-treading (rotation of the cell membrane around the center of mass)). So they result in macroscopic rheological changes that affect the whole cardiovascular system (Figure 1).

*Corresponding author: Pedro Cabrales, University of California, San Diego Department of Bioengineering, 0412 9500, Gilman Drive La Jolla, CA 92093-0412, USA, Tel: (858) 534-5847; E-mail: pcabrales@ucsd.edu

Received October 27, 2012; Accepted October 29, 2012; Published October 31 2012

Citation: Cabrales P (2012) Cardiovascular Signaling Malfunction Induced by Stored Blood Transfusion. J Blood Disorders Transf 3:e103. doi:10.4172/21559864.1000e103

Copyright: (c) 2012 Cabrales P. This is an open-access article distributed under the terms of the Creative Commons Attribution License, which permits unrestricted use, distribution, and reproduction in any medium, provided the original author and source are credited. 
Citation: Cabrales P (2012) Cardiovascular Signaling Malfunction Induced by Stored Blood Transfusion. J Blood Disorders Transf 3:e103. doi:10.4172/2155-9864.1000e103

Page 2 of 2

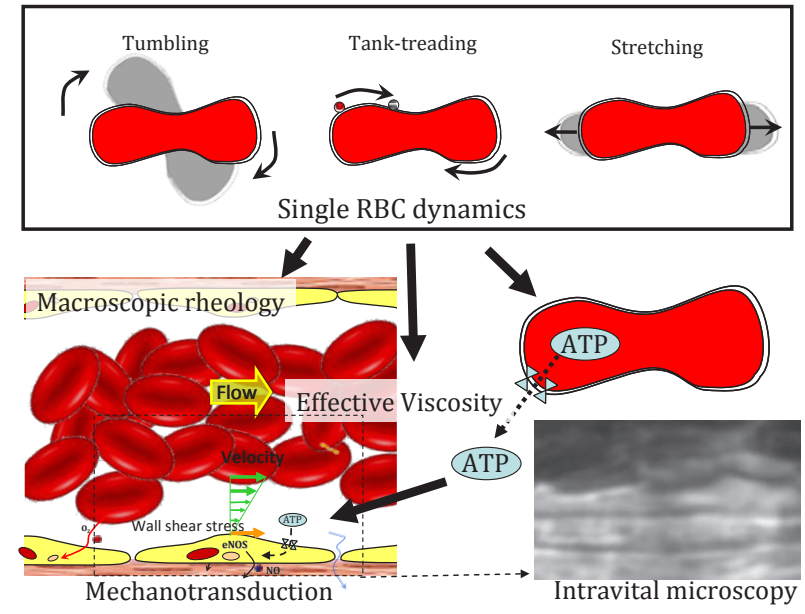

Figure 1: Multi-scale links between RBCs dynamics, shear viscosity, ATP release, and shear stress endothelial NO generation.

The transitions from tumbling, to tank-treading, to stretching are physically determined by the stress exerted by the flow; transitions are determined by spectrin-actin network remodeling; Shear mediated ATP is release from RBCs through transmembrane channels; Shear mediated NO generation; In vivo analysis using intra-vital microscopy.

\section{References}

1. Klein HG, Spahn DR, Carson JL (2007) Red blood cell transfusion in clinical practice. Lancet 370: 415-426.

2. Kuehnert MJ, Roth VR, Haley NR, Gregory KR, Elder KV, et al. (2001) Transfusion-transmitted bacterial infection in the United States, 1998 through 2000. Transfusion 41: 1493-1499.

3. Nordmann AJ, Bucher H, Hengstler P, Harr T, Young J (2005) Primary stenting versus primary balloon angioplasty for treating acute myocardial infarction. Cochrane Database Syst Rev: CD005313.

4. Koch CG, Li L, Sessler DI, Figueroa P, Hoeltge GA, et al. (2008) Duration of red-cell storage and complications after cardiac surgery. N Engl J Med 358 : 1229-1239.

5. Leal-Noval SR, Muñoz-Gómez M, Arellano-Orden V, Marín-Caballos A, AmayaVillar R, et al. (2008) Impact of age of transfused blood on cerebral oxygenation in male patients with severe traumatic brain injury. Crit Care Med 36: 12901296.

6. Hayes MA, Timmins AC, Yau EH, Palazzo M, Hinds CJ, et al. (1994) Elevation of systemic oxygen delivery in the treatment of critically ill patients. $\mathrm{N} \mathrm{Engl} J$ Med 330: 1717-1722.

7. Gong MN, Thompson BT, Williams P, Pothier L, Boyce PD, et al. (2005) Clinical predictors of and mortality in acute respiratory distress syndrome: potential role of red cell transfusion. Crit Care Med 33: 1191-1198.

8. Marik PE, Corwin HL (2008) Efficacy of red blood cell transfusion in the critically ill: a systematic review of the literature. Crit Care Med 36: 2667-2674.

9. Spinella PC, Perkins JG, Grathwohl KW, Beekley AC, Niles SE, et al. (2008) Effect of plasma and red blood cell transfusions on survival in patients with combat related traumatic injuries. J Trauma 64: S69-S77.

10. Kor DJ, Van Buskirk CM, Gajic O (2009) Red blood cell storage lesion. Bosn J Basic Med Sci 9: 21-27.

11. Lion N, Crettaz D, Rubin O, Tissot JD (2010) Stored red blood cells: a changing universe waiting for its map(s). J Proteomics 73: 374-385

12. Card RT (1988) Red cell membrane changes during storage. Transfus Med Rev 2: 40-47.

13. McCue JP, Vincent JM (1981) Changes in red blood cell membrane phosphate concentration during blood bank storage. Transfusion 21: 107-112.

14. Dumaswala UJ, Zhuo L, Jacobsen DW, Jain SK, Sukalski KA (1999) Protein and lipid oxidation of banked human erythrocytes: role of glutathione. Free Radic Biol Med 27: 1041-1049.

15. Cabrales P (2007) Effects of erythrocyte flexibility on microvascular perfusion and oxygenation during acute anemia. Am J Physiol Heart Circ Physiol 293: H1206-H1215.

16. Gonzalez-Alonso J (2012) ATP as a mediator of erythrocyte-dependen regulation of skeletal muscle blood flow and oxygen delivery in humans. $J$ Physiol 590: 5001-5013. 